\title{
A study of a new teaching mind set: Redirecting attention away from the instructor and putting attention on the learner and the learning
}

uirak Kim

Yong In University, Republic of Korea

\section{ABSTRACT}

Objectives: Currently, many universities have been emphasizing the importance of more liberal (student-centered) education. However, there has been neither practical support nor an appropriate system for it. The purposes of this study are to show various kinds of problems arising in operating liberal education courses within the universities in Korea; to explore teaching methods utilizing e-learning in general education at university level; and to suggest corrective measures where necessary.

Methods: A descriptive exploratory approach underpinned this project. This involved literature searches, exploration of findings and application in the course development, testing alternative student activities, encouraging more student self-direction in studies beyond the traditional classroom and capturing the students' existing engagement with information technology.

There was also a need to find a way in which an instructor, who is willing to introduce e-learning to general education, could easily utilize e-learning in their courses. In particular, considering that the features of general education are often similar or even the same in the way they are begun and maintained, I have suggested e-learning courses that many universities could utilize in collaboration with each other.

Results: In an effort to stimulate the communal utilization of general education among universities, not only the content producers but also content users need to cooperate each other in order to achieve quality of e-learning content and processes in general education.

Conclusion: Collaborative projects can encourage social interaction among students, making it easier for them to learn from one another and for those of varying skill levels to support their peers. 


\section{INTRODUCTION}

It is no secret that technology is changing the world around us. Specifically, the impact of technology in the classroom has been slow but is constantly evolving. Smartphones and tablets allow students to have easier access to information and the internet has opened up a wealth of knowledge to students of all ages. At the university level, there is a new type of learning that is redefining how educational content is delivered. In other words, we cannot close our eyes to the radical and rapid changes taking place in this Electronic Age. The times have changed locally and across the world. South Koreans should catch the change agenda and cope with it actively and swiftly. Otherwise, we will fall behind in international competition around high quality contemporary educational approaches.

Today students drive change in learning environments around the world. The technology, with which the digital natives have matured, has induced today's students to "think and process information fundamentally differently from their predecessors" (Prensky, 2001, 11). Unlike lecture-based classrooms, incorporation of active learning strategies into the classroom is now critical in order to reach many information literate students. As Prensky says, "A sense of urgency to adapt to Millennials' learning preferences is heightened as educators increasingly struggle to capture the attention of today's students. Unlike previous generations, the Millennials reared on rapidly evolving technologies demonstrate decreased tolerance for lecture-style dissemination of course information" (20).

\section{Background}

It is no longer a secret that technology changes mankind. In particular, the technological impact on classrooms has ceaselessly evolved. Currently, students easily can get access to information through smart phones, tablets and personalized computers (PCs). Moreover, the internet provides more readily accessible and abundant knowledge. Thus, a new ground-breaking method of learning is working against the classical manner of lecturing; this approach came into the picture assuming the form of either e-learning or MOOC (Massive Online Courses). On the other hand, giving a lecture may be significantly effective in terms of teaching, but it has a quite contrary outcome in the eyes of learners. Under these educational circumstances, their needs to be a change in the role of the instructor who is a facilitator, actively participating in classroom work, whose important role lies in leading students to recognize various perspectives on problems. Similarly, online education has provided a possibility of a more effective teaching methodology by sharing knowledge in a broad widely dispersed manner.

Started in the United States (US), the disruptive and revolutionary MOOC shakes the foundation of the authority of conventional accreditation systems and providers' exclusive rights to tuition fees as well. Indeed, students in the past had hardly any interaction with professors or other students. Recently, a videotape was used in many distance learning initiatives, but it was criticized for its passivity. On the other hand, the multimedia generation had popularized distance learning, allowing new possibilities. However only computers and the web could unite forces to provide new e-learning infrastructure, mainly built upon networks and communities on-line.

With the growing popularity of e-learning, many have asked whether this delivery mode is really a big innovation after all. Aren't they just an online resource after all, a kind of digital textbook? If so, is that really a big innovation? Let me explore some questions, first by comparing and contrasting e-learning with books, and then, exploring a few case studies. 
Is e-learning merely an intellectual diversion for the well educated and well-off? Does it provide any tangible benefits? As I am myself an educator at the university level, I can see that a new e-learning infrastructure is putting attention on the learner and is a double-edged sword: It can indeed change education but could also impact my own career in education. While universities will always need professors, the role of professors will change with e-learning-adapting and creating course material for e-learning can be time consuming.

\section{Purpose of the project}

Teaching should not be about demonstrating the capability of the person to prepare a lesson but about helping learners so that they can learn something of importance to their learning goals. Without taking into consideration the learner's circumstances and maintaining a one-sided approach to teaching without raising questions, a teacher can deprive learners of the opportunity for thinking and or they might even destroy their thought processes. When it comes to traditional learning, classroom lectures need more time to focus on applying, understanding, and remembering rather than creating, evaluating or analyzing. In addition, the teacher might give students new knowledge by lecturing during class. Students do not work on assignments and projects in classroom with peers, thus being more active and self-directed elsewhere. Presently if students cannot figure out how to discover and apply their knowledge to an assignment on their own, they are stuck and teachers may not be available to act as a coach. However, learners are not the object of instruction but the central subjects of learning, making knowledge as well as being the companions of forming learning through mutual communication and cooperation.

It is unavoidable in the current environment to introduce new online systems for educational purposes; there are no other ways to cope with the emergence of technology that impacts the distribution of rapidly changing knowledge. There have been many e-learning courses available for use in homes. Now many undergraduate courses in North America pick up the teaching methodology known as "Flipped Learning". Since revising higher education laws in 2008, open cyber universities have had authority to act as regularly accredited institutions. Information technology should be promoted as a useful mechanism to enhance the capability of collaborative learning through communication so that learners can raise questions and instructors can design learning events that lead them through the application of methods such as Problem Based Learning (PBL) not only in the field of the Humanities but also in other disciplines. Of course, considering the need to tailor learning events to accommodate different learners' point of views, it is desirable to pursue trends occurring at the local and global levels. For this purpose, it is time for Korean educators to consider renewed ways of collaboration, along with shared content development and technological cooperation for gradually transforming approaches to instruction as well as making routine the offering of online courses.

Newly attempted approaches to adoption of online systems could be nothing less than an academic revolution, which will certainly be faced with friction and resistance in every way. Koreans need to deal with three critical success factors arising from factors such as; technology (platform, content, and learning analytics), human (faculty, students, and other staff) and organization (commitment, policy, incentives, and culture). IT-enabled active learning, that is, education that offers the provision of automated instant feedback and monitoring functions, peer instruction as well as the methodology around PBL. However, if we pay close attention to the fundamental grounds for 
introducing new e-learning systems, it can be viewed as a democratization of knowledge and information which could be the foundation of the prosperity of academic growth of the humanities as well as the liberal arts and sciences. Thus, I have explored the strengths of offering more flexible ways for delivering the liberal arts and sciences and how to design events focused on these in terms of academic activities. The primary goal of this study was to maximize student outcomes and to change what the students spend their time doing in class where they have access to their best learning tool, utilizing the face-to-face time I have with my students. For this purpose, the content resource is provided for homework through the use of pre-recorded lectures. This allows the student and me to utilize the time spent in class on deepening the student's understanding of such concepts through examining more complex problems.

Unfortunately, we have spent too much class time delivering the content in our traditional classrooms. This meant the students did not have as much time to explore the concepts at a higher level in class with the support of their instructors. As usual, they were instructed to complete the high order problem solving questions that required them to critically explore the concepts on their own for homework. In connection with this, let me deal with the impact of a new online education system putting attention on the learner in the Humanities: There are advantages and disadvantages. For this purpose, this study began with an analysis of activities related to online education in other countries.

\section{METHOD}

A descriptive exploratory approach underpinned this project. This involved literature searches, exploration of findings and application of these in course development, testing alternative student activities, encouraging more student self-direction in studies beyond the traditional classroom and capturing the students' existing engagement with information technology.

Educators are certainly riding the wave of the global shift to online channels for information gathering; and they are, perhaps, the first generation of Web-based educators to step into a second stage of the use of technology in learning design and delivery. Furthermore, e-learning provides a life-changing opportunity for those who are less advantaged and have limited access to educational opportunities. These educators create something native to the Web that takes advantage of what the electronic environment can do, rather than simply trying to virtually mimic a classroom. As Groom (2014) puts it, online education that first appeared in 2008 might be the first truly Web-native form of teaching and learning. Ironically, most people who start online education do not finish: Just $4 \%$ of Coursera users who watch at least one course lecture go on to complete the course and receive a credential. However, given the large number of users involved, the absolute reach of online education is still significant.

The background of MOOC shows it as a new form of online learning derived from OER (Open Educational Resources) and OCW (Open Course Ware). MOOC started in America as a means of mutual communication and connectivism by snatching learners of higher education from e-learning and cyber universities (http:// en.wikipedi.org/wiki/Massive_open_online_course). Even three years ago, diverse ways of MOOC services had been developed in America, including edX, Coursera, and Udacity. Those countries such as Britain, America, and France are pursuing open education, enhancing higher education access including the liberal arts by sharing with larger numbers of more active learners. Koreans have to 
investigate these options for course delivery.

Much of the discussion around online educations has been about participation and engagement, and rightly so, because these are important issues. However, even in the cases where learners fully participate, how do we think about how much educational value is actually provided in the online approach? Some people may point to satisfaction scores or exam results, but these do not seem tailored to the types of issues arising in learning experiences.

Using a video production class as a pedagogical model for teaching and learning, for the past several months I have experimented on students taking my classes and others to see how students are engaged in active participation or can inquire about lecture content, test their skills in applying knowledge, and interact with one another in hands-on activities in those classes. I temporarily gave up my frontof-the-class position in favor of a more collaborative and cooperative contribution to the teaching process. There was a concomitant change in the role of students, many of whom are used to being cast as passive participants in the education process; I have provided resources to them, while giving them greater impetus to experiment. Activities were student-led, and communication among them can become the determining dynamic of a session devoted to learning through hands-on work. Short tutorial video lectures let students move at their own pace, rewind to review portions, and skip through sections they already understand. This enables them to prepare to undertake creative projects with their peers. A particularly successful example came about about 100 students at Yong In University.

In the spring of 2016, the Department of International Relations at Yong In University faced a series of obstacles as I approached them to teach students in a different way.
I had a deep desire to improve student learning, but the reality was not favorable due to diverse issues that almost seemed insurmountable. However, with some out-ofthe-box thinking, lots of time, and highly motivated determination, I tried to develop and apply a new method of teaching methodology putting attention on the learner, which is so called "Peer Instruction" based on open source materials along with the standards of Yong In University curricula.

More specifically, students watch the recorded lesson before class then come to class and do the traditional homework projects in class. My innovations resulted in increases in student performance. Students work together during the peer instruction process. Students learned the materials before class, and then I asked a series of conceptual multiple choice questions in class. I put up the first question, students then answer it and share their answer with me without talking with any of their peers. Then students discussed their answers with their peers and try to convince their peers of the value of their answers. The students with the correct answers are typically able to convince their peer who had the wrong answer of what the right answer is and why. Then this process was repeated on each question.

In my current classroom, I created a lecture style lesson that students access online and watch during (self-directed learning) homework before the lesson. This allowed students to come into class already 'front loaded' with the required stimulus material for knowledge acquisition and learning processes. We can then utilize the classroom time to work on the exercises that allow students to gain a deeper understanding of problem solving concepts. Each student has watched the lecture for homework like the rest of the class. They use class time to demonstrate their understanding and then have the time to be extended in 
this. They watch the lecture for homework with the ability to pause, rewind and re-watch as many times as they like. This allows them to follow the lecture at their own pace. When students come back into classes on campus we can work on ensuring they understood the concepts within the lecture and continue with the exercises that allow them to gain a deeper understanding. I typically manage 4 to 6 questions like this then students use the rest of the time to work on their problems; their peers and I are there to answer any questions that might come up. I question the students on the details in the previous night's video. This ensures the students understood the content and highlights any areas they may require further assistance with. After this, we get on with the learning and this is the real advantage of the approach. The students get to maximize the time they spend engaging with the knowledge, concepts, processes and problem solving. While I could divide their time between those who require assistance and those who are looking to be extended, I spend most of my time working with the students to help deepen their understanding of the material. What it does is allow me to increase are the student-teacher interactions. The real advantage for those students is the time the students get in class to complete the exercises with my assistance. Now students who miss classes can still keep up with the work by watching the online lectures. This also works for students who wish to go back and review previous lectures, something they are not able to do in the traditional classroom. The following table is how I previously spent my time in my traditional classroom and how I now spend my time in my class.

[My Current Classroom Activities]

\begin{tabular}{|c|}
\hline $\begin{array}{c}\text { Participation and Creating Activities } \\
\text { (Time Spent 30\%) }\end{array}$ \\
Evaluating and Discussion \\
(Time Spent 30\%) \\
Analyzing and Investigation \\
(Time Spent 20\%) \\
\hline
\end{tabular}

[My Current Homework Project Lecture]

\begin{tabular}{|ll|}
\hline Project Applying $\quad$ (Time Spent 20\%) \\
\hline Project Understanding $\quad$ (Time Spent 0\%) \\
\hline Project Remembering $\quad$ (Time Spent 0\%) \\
\hline
\end{tabular}

Table 1. Traditional Classroom Time 
In my traditional classroom, I spent most of the time giving 'directed lectures' on the materials. Students of Yong In University are often absent from classes. This could be due to illness or extra-curricular activities: I found that students with heavy sporting commitments often miss classes due to training or sporting events. Those students find it difficult to catch up on missed work when they have missed the classroom lecture. Traditionally in most classes, I would give a lecture style lesson to the students to front load them with required knowledge and process. The students would then practice this in the class with whatever class time was left, with an expectation that their learning would continue at home where they would do more exercises to help reinforce the concepts. This led to the students not having enough class time to fully engage with the activities that allow them to gain a deeper understanding of the materials. This traditional model has a few flaws due to the lecture style delivery of content to the entire class meaning it is difficult to personalize the lesson to student needs. While I was lecturing, students were getting bored. They understood the materials in a short amount of time and sat through the rest of the lecture while I was either answering other student's questions or giving more examples to ensure other students understood the material. Sometimes the struggling students complained that they have not finished writing down the material on the board before I am ready to move on. Those students required my assistance in completing the exercises that were set.

In-classrooms, time is used for open discussion, a featured guest speaker, or hands-on problem solving where instructor support is supplemented by many students; this provided me with free interactive software enabling students to discuss, apply, and get feedback from what they hear in lectures. During class sessions, I, as an instructor, function as a coach or an advisor, encouraging students in individual inquiries and their collaborative efforts. Unlike

[My Traditional Homework Project Lecture]

\begin{tabular}{|ll|}
\hline Project Applying $\quad$ (Time Spent 20\%) \\
\hline Project Understanding & (Time Spent 30\%) \\
\hline Project Remembering & (Time Spent 30\%) \\
\hline
\end{tabular}

[My Traditional Classroom Activities]

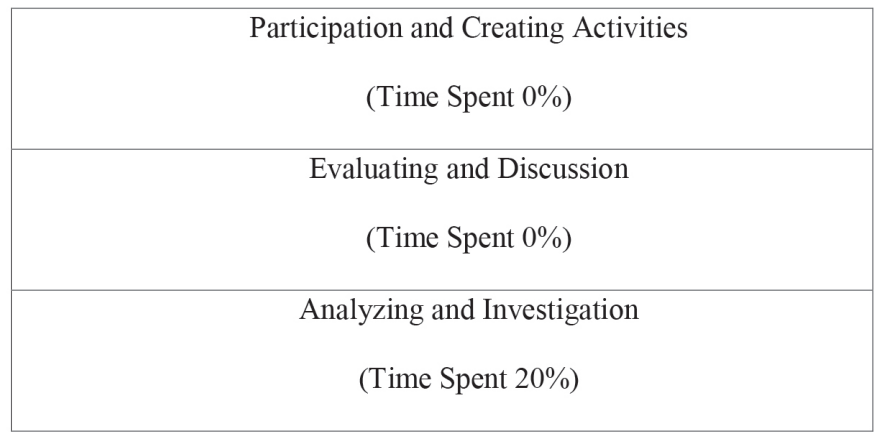

Table 2. 
the typical lecture and homework elements of a course, I have had students view short video lectures at home before the class session, while in-classrooms, time is devoted to exercises, projects, or discussions.

For the past several months, approximately more than 300 students have been taking classes, in several English courses, Students come from remarkably different academic backgrounds at Yong In University. Before they attend each class, they have watched videos of short lectures recorded or recommended by their instructors. Each lecture comes with brief online quizzes that offer them immediate feedback on whether they missed any essential points. Online quizzes or activities can be interspersed to test what students have learned. Immediate quiz feedback and the ability to return to lecture segments may help clarify points of confusion. Instructors might lead in-class discussions or turn the classroom into a studio where students create, collaborate, and put into practice what they learned from the lectures they viewed outside class. As on-site experts, instructors suggest various approaches, clarify content, and monitor progress. They might organize students into an ad hoc workgroup to solve a problem that several are struggling to understand. More specifically, this approach represents a comprehensive change in the class dynamic. Likewise, every time they enter classes, they glance at the schedule on the whiteboard. For the first half hour, teams will discuss how the content of the video lectures impact on that particular English class: I circulate among the tables to see if anyone has questions.

In the second half of the class, team monitors each retrieve two flat boxes from the front of the class. One box contains a stack of pins and various leaves preserved in plastic. Each square is labeled with specific topics or questions related to those classes. During the next half hour, each team is to identify those issues. Likewise, students are on hand, directing attention to clues and sometimes challenging their choices and curiosities.

As they leave, they reflect that the hands-on activities have given them a far better grasp of the information and more confidence in what they have learned when compared to outcomes from in-class lecture. At the same time, collaborative projects encourage social interaction among students, making it easier for students to learn from one another and through those of varying skill levels to support their peers.

As these types of classes become more popular, new tools may emerge to support the out-of-class portion of the curriculum. In particular, the ongoing development of powerful mobile devices will put a wider range of rich, educational resources into the hands of students, at times and places that are most convenient for them, supplementing traditional out-of-class work with video presentations and supporting project-based and lab-style efforts during regular class times.

\section{RESULTS AND LIMITATIONS}

There are downsides to this approach as well. Recording lectures requires effort and time on the part of instructor, and out-of-class and in-class elements must be carefully integrated for students to be motivated to prepare for classes. As a result, introducing change means additional work and may require new skills for the instructor. On the students' part, they have been known to complain about the loss of face-to-face lectures, particularly if they feel the assigned video lectures are available to anyone online. Students with this perspective may not immediately appreciate the value of the hands-on portion of the model, wondering what their tuition brings them that they 
could not have gotten by surfing the web. Those who see themselves as attending class to hear lectures may feel it is safe to skip a class that focuses on activities and might miss the real value of collaborative learning.

In recent years, online education events are expanding, beyond the classroom-replication experience, allowing them to broaden their scope, and be something more. Which option will dominate? Will they be commercialized and commoditized, or will they become more innovative and diverse? Or is that too extreme a dichotomy? Let's take a closer look at some key aspects of book-centric vs. online education. Although it would be difficult to speculate on the extent of this, there is a connection between online education and books. Books and online educations are not substitutes for one another, but are very different, and in fact are good complementary channels from which to access information. Books may have visual illustrations and can go into more detail and depth. A book would aim to be comprehensive in its chosen topic, while most online educational materials are introductory in nature. They also make it really easy to see what a particular statement might be based on.

On the other hand, online education events are much more like digital textbooks. They allow for a full use of video, mastery learning through extensive quiz questions by allowing students to take and retake quizzes until they really understand a concept. Online education enables learners to rethink the organization of the material and this usually results in an improved learning experience. Indeed, animations make strong impression; and a picture is worth a thousand words. A moving picture is worth two thousand words by briefly covering the main points. Animation can compress what would ordinarily be an hour-long lecture into 6-7 minutes because it gets crystallized and synthesized. Why then is it that video can be more engaging than just a reliance on text? An effective video uses motion, different perspectives, and vivid metaphors and visuals to be effective. Likewise, online education allows for vivid animation and motion, which retains learners' attention on multiple cases.

So far there have been so many kinds of online education course along with humanities, liberal arts and sciences, natural sciences, computer sciences, music, business administration, mathematics, and others. However, the ultimate goal of online education is to satisfy the intellectual curiosities of learners in their specialized fields. The future educational events will certainly evolve into inclusion of learners' creative inventions and their cooperation that comes out of experts' specialization through the performance of superb online education and understanding of data submitted by learners by using various simulations and developing content such as Coursera, edX, Udacity, FUN, and Future Learn. Under these educational circumstances, the ideal online learning space leads to collaboration along with diverse learners regardless of age and specialized jobs by finding solutions and cooperating with each other. At home and abroad, traditional education has been inflexible and stereotypical. Moreover, it was not possible to collaborate between foreign universities and research institutions in a fixed semester system. Knowledge was transmitted only in classrooms through homework, projects, and explanations provided by the educator. However, future lectures will take different shapes in terms of watching videos and digital outside classrooms. On the other hand, students and professors will engage in active debate and open discussion in small groups, through which learners can easily understand complex issues and develop their potential.

The population of school-aged children decreases 
in Korea along with the percentage of students who go on to universities; many drop out of school. So, what is the solution to the emerging problem of supporting educational infrastructure in Korea? It is transformation of the existing paradigm. As digital natives, students of the new generation grew up in the midst of the internet culture and they promote mutual understanding between society and their brackets through internet. Moreover, it increasingly becomes only possible to communicate with them through the medium of online education. What is more important is that this should be studentoriented education. In other words, now it is time to take into consideration a new concept of learning, by taking teaching methodology out of traditional classrooms to offer a sustainable model to engage the new generation students.

Likewise, colleges facing competition now have to more deeply study securing ways and means of applying online educational strategies; the cramming system of education for a large number of students will certainly lose its foundation. Online education is not now the complementary component of stereotypical education; it is a pivotal method to gratify new learners by promoting it to students so that they can settle issues for themselves by asking them for the best options based on this preposition. I came to pay attention to the boundless educational aspects of working beyond physical restrictions. It is now a Korean style of online education, putting attention on the learner.

More specifically, putting attention on the learner will play a crucial role in stimulating learners in terms of an operational plan for effective online education. Based on the establishment of new online education infrastructure, it would be possible to pave the way for more effective use of online education through deeper research on curricula, subjects, teaching-learning method, administrative support for the settlement of problems along with identification of any strength and weaknesses.

One of the major factors in course redesign is the time it takes to do it well. I recommend pilot testing the new model that I have applied with a single class before engaging in a complete redesign. Whether you have designed your course around learning outcomes or by units, the following questions may help you identify a good place to start. What classes do you currently have an in-class activity that you rarely have time to complete during the class? What practices do students need inside of class to prepare them for the larger assignment that will be completed after-class? The after-class portion may consist of a wide variety of activities including completing the work started in class or reading more deeply about the topic or working together on a larger assignment. Otherwise, you had better spend class time engaging students in application activities with feedback. In addition, keep reading materials or online video content simple at first, by either relying on your current resources or using existing online content rather than creating your own. In this way you will extend learning beyond class through individual and collaborative practice. Students gain experience applying course content during class time, but they may also need additional practice after class. Likewise, extending what happens inside the class to outside the class is a crucial step for students to gain mastery and meet the learning outcomes. The crux of the issue is figuring out for your class how class time could be repurposed in ways that provide students with an appropriate level of challenge while leveraging your expertise as a guide. There are many possibilities for infusing a class with collaborative learning experiences. Simply put, the point of my new model is to move the application-oriented homework into the classroom and to move the lecture to before class. 


\section{CONCLUSION}

In conclusion, in a traditional lecture, students often try to capture what is being said at the instant the speaker says it. They cannot stop to reflect upon what is being said, and they may miss significant points because they are trying to transcribe the instructor's words. By contrast, the use of video and other prerecorded media puts lectures under the control of the students: they can watch, rewind, and fastforward as needed. Students can gain necessary knowledge before class and instructors can guide students to actively and interactively clarify and apply that knowledge during class. This approach supports instructors playing their most important role of guiding their students to deeper thinking and higher levels of application.

\section{REFERENCES}

Barr, R. B. "From Teaching to Learning: A New Paradigm for Undergraduate Education." Change (27(6): 12-25. Bergmann, Shane. http://www.shane-mason.com

Chickering, A. W. "Seven Principles For Good Practice In undergraduate Education." American Association for Higher Education Bulletin. Retrieved from http://www. eric.ed.gov ED 282491.

Groom, Jim. http://www.edtechresearcher.com/wp-content/ uploads/2014/10/SES and-MOOC-EnrollmentLAK-10_14_submitted.docx (2014)

Hansen, J. \& Reich, J. (2014). Socioeconomic Status and MOOC Enrollment: enriching Demographic Information with External Datasets, In progress, available at Ho, A., Reich, J., Nesterko, S., Seaton, D., Mullaney, T., Waldo, J., \& Chuang, I. (2014). HarvardX and MITx: The first year of open online coursers, HarvadX and MITx Working Paper No.1.

Jordan, K. (2014). Initial Trends in Enrolment and Completion of Massive Open Online Courses, The Internaitonal Review of research in Open and Distance Learning, 15(1), 133-160.
Kevat, P., Open2Study Research Report - October 2013 (cohort 4), Open2Study \& Open Universities.

Klobas, J. (2014). Measuring the success of scalable open online courses, Performance Measurement and Metrics, 15(2), 145-162.

Ministère de l'enseignement supérieur et de la recheche(2013). Fance UniversitéNumérique, Le numérique au service d'une Universitéen mouvement. Dossier de Presse, Octobre 2013. http://cache.media.enseignementsuprecherche.gouv. fr/file/France_universite_numerique/83/6/DPGF_SC1_ BAT_272836.pdf

Prensky, M. R. Teaching Digital Natives: Partnering for Real Learning. Newbury Park, CA: Corwin, 2001. "Digital Natives, Digital Immigrants." On the Horizon. 9(5): 1-6. http://moocnewsandreviews.com/a-short-history-ofmoocs-and-distance-learning/\#ixzz 4EvDr9GSD

Rosewell, J. (2014). OpenupEd label, quality benchmarks for MOOCs. Heerlen, The Netherlands: European Association of Distance Teaching Universities (EADTU).

Schaffhauser, Dian. (Jan. 21, 2014). Georgia Tech MOOCBased Degree Program Turns Away Nearly 2,000 Applicants. Campus Technology, Accessed at http:// campustechnology.com/articles/2014/01/21/georgia-techmooc-based-degree-program-turns-away-nearly-2000applicants.aspx University of London (2013). Massive Open Online Course (MOOC) Report 2013. University of London International Programmes.

White, S., Davis, H., Dickens, K., Leon, M., \& Sanchez-Vera, M. (2014), Communications in Computers and Information Science, In press.

Williams, K; Kear, K and Rosewell, J (2012). Quality Assessment for E-learning: a Benchmarking Approach (2nd ed.). Heerlen, The Netherlands: European Association of Distance Teaching Universities (EADTU). Accessed at http://e- xcellencelabel.eadtu.eu/tools/manual. 
